- Michael HB Raditya

LARAS (Studies of Music in Society)

\title{
Mengartikulasikan Relasi Musik dengan Radikalisme
}

\begin{abstract}
A B S T R A C T
This article deals with relation between music and radicalism. In fact, religion and politics are more related with radicalism. In art perspective, visual art was more related with radicalism rather than music position-especially in Indonesia. In Indonesia music had minor relation with radicalism. According this fact, $i$ would like to explore about music with radicalism with link with several songs, genres, and moda of production-especially relate with definition of radicalisme was rooted movement. The result that i got so far is songs, genres, and mode of production relate with counter-culture. Through counter-culture, radicalism movement that used by music can be running with a different portion, inter alia: change old system to new system, and deal with daily activity as a counter. This result made me more brightly to articulate that pathern and logic of radicalism not only about practical measured, but relate with ideology things.
\end{abstract}

Keywords: Alternative System, Counter-culture, Music, Radicalism, Youth

\section{PENGANTAR}

Tidak dapat dipungkiri bahwa isu radikalisme tengah meradang di Indonesia belakangan ini. Pelbagai pemicu marak terjadi, mulai dari ihwal politik, hingga tertaut pada ihwal agama serta rasial tertentu. Khususnya untuk beberapa contoh terakhir, kasus yang lazim teridentifikasi dalam aksi radikalisme kerap tertaut dengan agama. Dalam ihwal ini, kepercayaan agama tertentu kerap berkontestasi dengan pluralitas untuk memperebutkan 'kekuasaan'. Penyikapan atas ihwal ini pun beragam, bagi sebagian orang hanya sebatas mengumpat dan mengutuk, tetapi bagi sebagian orang lainnya, mereka akan berlaku sebaliknya, memaklumi. Sebuah sikap dikotomis dari masyarakat dalam menyikapi radikalisme, terlebih terpaut soal agama. Kecenderungan ini pun turut disadari dan dibaca oleh para scholar yang tidak hanya berasal dari Indonesia, tetapi dunia. Seakan membaca konstelasi yang terjadi belakangan, pelbagai scholar pun merespon dengan tanggap segala ihwal radikal yang tertaut dengan agama, khususnya di Indonesia. Sebagai contoh, sebuah penelitian yang ditulis oleh Andri Rosadi (2006) tentang gerakan Islam yang tengah naik daun belakangan ini, Front Pembela Islam (FPI). Dalam penelitiannya, Rosadi mengungkap gagasan radikalisme ormas tersebut, juga turut mengulas tentang relasi kuasa gerakan FPI hingga Habib Rizieq, imam besar mereka.

Selain itu, pembahasan gerakan islam lain turut dibahas oleh Abdul Salam pada tahun 2004. Di dalam penelitiannya, Salam menautkan ihwal radikalisme dan korelasinya dengan agama Islam. Salam 
merujuk pada sebuah kelompok Majelis Mujahidin Indonesia yang notabene terlahir pada era reformasi, secara lebih lanjut muncul setelah maraknya partai politik Islam. Bagi Salam, organisasi Islam tersebut dibentuk dalam rangka menegakan syariat Islam, dengan misi "Tabtiqus Syari'ah." Alhasil pelbagai gerakan hingga pada tataran yang dianggap 'radikal' turut dilakukan. Jika merujuk pada dua contoh penelitian di atas, kita dapat melihat bahwa pembahasan akan radikalisme yang paling menarik merujuk pada agent dari radikalisme tersebut.

Alih-alih hanya perkara gerakan, seluk beluk radikalisme dalam Islam pun turut diartikulasikan oleh banyak penulis lainnya, salah satu di antaranya adalah Deni Asy'ari yang melakukan penelitian di tahun 2009. Asy'ari mengidentifikasikan pelbagai gerakan Islam Radikal di Indonesia dengan metode taxonomi yang merujuk pada rezim di Indonesia, seperti: di awal kemerdekaan, orde baru, dan reformasi. Dalam penelitian Asy'ari, ia turut membagi gerakan Islam Radikal secara dikotomis jika melihat pola gerakan yang dibuat, yakni aksi struktural dan aksi kultural. Tidak hanya itu, poin utama dari penelitian Asy'ari adalah melihat kampus dan aktivitasnya menjadi media dalam kaderisasi aktivis gerakan Islam radikal. Dalam arti penelitian Asy'ari merupakan model pembentukan gerakan yang ternyata telah dibina pada ranah kampus. Ihwal tersebut dapat disederhanakan dengan internalisasi ideologis. Pembahasan yang dilakukan Asy'ari cukup menjelaskan bahwa kecenderungan gerakan radikal tidak terjadi begitu saja, turut ditanamkan, baik secara sadar ataupun sebaliknya. Hampir serupa dengan telaah habitus milik Pierre Bourdieu yang mengartikulasikan individu secara detil, baik praktik, modal, arena, dan habitus itu sendiri.

Tidak hanya itu, turut terlacak pelbagai buku radikalisme dan Islam yang tidak kalah menarik dibahas, seperti pada buku yang berkembang di tanah air, antar lain: Islam dan Radikalisme di Indonesia karangan Endang Turmudi dan Riza Sihbudi (2005), Agama dan Radikalisme di Indonesia karangan Bahtiar Effendy dan Soetrisno Hadi (2007), Radikalisme di Dunia Islam karangan Deny Suito (2005), dan sebagainya; hingga buku baboon seperti Roots of Radical Islam in Central Asia karangan M.B. Olcott (2007), atau Islamic Political Radicalism: A European Perspective karangan Tahir Abbas (2007). Atas telaah yang dilakukan, telaah radikalisme lebih dominan pada ihwal agama.

Alhasil pencarian telaah radikalisme dengan konotasi yang lain perlu rasanya di implementasikan guna memahami akan definisi ataupun teoretis akan terapan radikalisme itu sendiri. Jika menindak lanjuti penelusuran, terma radikalisme lebih populis digunakan pada persoalan gerakan perlawanan. Senada dengan pernyataan tersebut Sartono Kartodirjo (1992), seorang Sejarawan, menggunakan istilah radikalisme untuk menggambarkan gerakan protes petani yang menggunakan simbol agama dalam menolak seluruh aturan dan tatanan yang ada. Istilah radikal digunakan sebagai indikator sikap penolakan total terhadap seluruh kondisi yang sedang berlangsung.

Tidak hanya Kartodirjo, Kalam Jauhari pun turut menelaah radikalisme yang tidak berkenaan dengan agama, melainkan gerakan. Jauhari meneliti radikalisasi buruh kereta api di perkotaan Jawa pada tahun 1914-1926. Dari yang 
dilakukan Jauhari, ia menunjukan bahwa radikalisme turut disebabkan adanya jarak atau lapis kelas yang signifikan. Ihwal ini turut terungkap atas penelitiannya akan buruh kereta api yang memang mempunyai pola kehidupan yang berbeda dengan para tuan tanah dan kolonial. Pada abad 20, buruh kereta api melawan dengan radikal karena rasa ketidakadilan antar pegawai yang diklasifikasikan. Gerakan-gerakan radikal serta pemogokan kerap dilakukan secara massal dan mengakibatkan perindustrian berhenti. Bertolak dari contoh telaah radikalisme selain yang berkorelasi dengan agama, turut terlihat jelas bahwa radikalisme merujuk pada penolakan total.

Berkenaan dengan ihwal tersebut, seakan mengurai dengan tepat, Horace $M$. Kallen memberi bingkai yang lebih sederhana dengan kategorisasi terhadap radikalisme [dalam konteks sosial], yakni:

Pertama, radikalisme adalah respon terhadap kondisi yang tengah berlangsung. Lazimnya respon tersebut muncul dalam bentuk evaluasi, penolakan, atau perlawanan. Masalah yang ditolak dapat berwujud ide, lembaga, atau nilai-nilai yang dipandang bertanggungjawab terhadap keberlangsungan kondisi yang ditolak. Kedua, radikalisme tidak berhenti pada upaya penolakan melainkan terus berupaya mengganti tatanan tersebut dengan suatu bentuk tatanan lain. Kaum ini berupaya kuat menjadikan tatanan mereka sebagai pengganti dari tatanan sebelumnya. Dengan demikian, sesuai dengan arti kata 'radic', sikap radikal mengandaikan keinginan untuk mengubah keadaan secara mendasar. Ketiga, teguhnya keyakinan para kaum radikalis akan kebenaran ideologi yang mereka bawa. Alhasil keyakinan tersebut mengakibatkan munculnya sikap emosional yang berlebihan di kalangan mereka (via Seligman, 1972:1-54).

Dari telaah Kallen di atas, tegas rasanya yang diartikan sebagai radikalisme, yakni radikalisme sebagai sebuah respon; penggantian tatanan atau membuat tatanan baru.

Dengan telaah ini, maka sekiranya, kita dapat menyikapi pernyataan Kartodirdjo dengan tepat, yakni: "Gerakan radikal merupakan gerakan yang bersifat multidimensional, antara lain ditandai dengan terjadinya polarisasi, pilarisasi, spesialisasi, dan dikotomisasi berdasarkan agama, etnis, atau yang lainnya; ada gerakan yang bertujuan politis, ekonomis, sosial, dan ada gerakan radikal yang bersifat elitis atau sebaliknya populis" (1987). Alhasil kita sudah di dalam satu pemahaman yang cukup luas bahwa radikalisme tidak dikonotasikan sebagai serangan agama, terorisme, dan semacamnya semata, melainkan dapat merujuk pada pelbagai praktik di dalam kehidupan. Di mana setiap aspek kehidupan yang didasarkan pada konstekstualnya masing-masing menyimpan sikap radicnya masing-masing.

Berkenaan dengan aktivitas yang dianggap radic, telaah yang tidak kalah menarik dari radikalisme adalah peran pemuda sebagai pihak operasional dari gerakan tersebut. Jika merunut telaah atas radikalisme agama di atas, Asy'ari (2009) dalam penelitiannya "Radikalisasi Gerakan Keagamaan Mahasiswa Non Studi Keagamaan dalam Gerakan Islam Radikal", memang telah menyadari bahwa pemuda di kampus dikader sebagai calon 
baru atas kelompok radikal agama. Dalam ihwal ini, penelitian akan kaderisasi radikal memposisikan pemuda hanya sebagai objek, tidak menjadi subjek dalam gerakan tersebut. Padahal, perlu disadari bahwa pemuda merupakan tingkatan manusia dalam usia produktif yang tinggi. Di mana pemuda mempunyai peran signifikan dalam menentukan pelbagai aktivitas, baik secara personal ataupun komunal. Namun pemuda sebagai aktor intelektual dalam radikalisme tidak berlaku general dan lebih bersifat kasuistik, pasalnya banyak pemuda yang cenderung apolitis dan sekedar mengonsumsi semata.

Bertolak dari ihwal tersebut, di dalam artikel ini pembahasan akan ditujukan pada beberapa ihwal penting, pertama, telaah aktivitas pemuda dan radikalisme, dan kedua, pada kasusistik seni pertunjukankhususnya musik-Indonesia yang minim pembahasan. Salah satu alasan pemilihan aktivitas seni sebagai cara pandang dalam melihat pola pemuda dan radiklisme dibahas adalah kesadaran akan aktivitas pemuda yang berhubungan dengan seni kerap tidak diindahkan secara serius di Indonesia. Oleh karena itu, pembahasan akan aktivitas pemuda dan radikalisme melalui seni dirasa cukup menarik ditelaah. Terlebih pada telaah Laclau \& Mouffe (1986) menyatakan di mana radikalisme tidak serta merta mengcounter kemapanan, melainkan mentransformasi konstelasi sosial, ekonomi, dan politik yang diidamkan. Berkenaan dengan telaah Laclau dan Mouffe, maka dalam bingkai

\footnotetext{
${ }^{2}$ Gerakan radikal anak muda dipetakan menjadi tiga kategori, yakni: (1) radikalisme politik pemuda dengan gerakan sosial-politik untuk mengubah tatanan sosial, ekonomi, dan politik yang telah mapan (2) radikalisme gaya hidup pemuda sebagai bentuk protes dan 'politik keseharian' (lifepolitics) (3) radikalisme anak
}

inilah seni dapat ditautkan. Di mana aktivitas seni kerap digunakan sebagai aktivitas yang 'mengubah'.

Aktivitas yang mengubah pun tidak diandaikan sebagai tindakan yang represif dan anarkis, karena radikalisme tidak hanya bicara soal kekerasan, melainkan mengubah tatanan yang telah mapan, dan mengubah gaya hidup sebagai sebuah protes $^{2}$. Alhasil di dalam artikel ini, pembahasan terkait aktivitas seni dan pemuda yang ditujukan sebagai bentuk radikalisme akan coba ditautkan. Dengan ragam seni yang ditautkan, kita dapat sadar bahwa aktivitas radikal melalui seni turut termanifestasikan dalam membentuk sebuah keberlangsungan budaya, baik secara perlahan dan periperal, ataupun secara signifikan serta universal.

\section{PEMBAHASAN}

\section{Mengartikulasikan Radikalisme dalam Seni}

Tidak dapat dipungkiri bahwasanya radikalisme di dalam masyarakat yang tertaut dengan politik dan agama cukup mudah dilacak. Namun tidak dapat diindahkan bahwa radikalisme agama dan politik turut membuahkan penghancuran pada aspek lain. Salah satu yang contoh yang tidak terlalu jauh adalah penghancuran oleh kelompok radikal agama tertentu atas karya seni dan artefak di sebuah rezim. Penghancuran itu dilakukan oleh kelompok radikal agama di Timur Tengah, ISIS. Telah tercatat bahwa

muda yang 'mengambil jalan' kekerasan sebagai gerakannya baik dalam bentuk vigilantisme, paramilitary, dan terorisme (Term of Reference Yousure dengan tema Pemuda dan Radikalisme). 
ISIS telah menghancurkan artefak di Mosul Central Museum, Iraq $^{3}$ setahun lalu. Tidak lama berselang ISIS kembali melakukan pelbagai penyerangan serupa, seperti penghancuran Roman Amphitheater di Palmyra, Syria ${ }^{4}$ di awal tahun ini, dan masih banyak penghancuran lainnya oleh kelompok tersebut. Ihwal tersebut cukup disesalkan oleh pelbagai kalangan, karena penghancuran artefak dan karya seni di museum sama saja menghapus bukti sejarah kehidupan akan sebuah negara. Kendati banyak yang mengencam namun ISIS tetaplah beroperasi radic dalam menciptakan sistem agama menurut versi mereka.

Dari contoh di atas, seni memang telah menjadi korban atas radikalisme agama. Namun ihwal tersebut tidak dapat digeneralisir ke semua bentuk seni bahwa seni hanyalah sebatas objek. Pasalnya, seni turut ambil bagian dalam radikalisme, baik secara porsi ataupun relasi. Dalam ihwal ini, relasi yang dimaksud adalah seni tidak dapat berdiri dalam mengusung radikalisme, seni selalu tertaut dengan aspek lainnya. Hal ini mengejewantahkan bahwa seni selalu terkait dengan kontekstual masyarakat. Sedangkan porsi yang dimaksud di atas adalah tertaut dengan seberapa besar relasi dengan aspek lain dalam membentuk gerakan yang radic. Namun kontekstual memang sangat berpengaruh dalam sebuah gerakan yang radikal. Pasalnya radikalisme turut membutuhkan susunan sistem baru guna menggantikan sistem lama secara holitsik dan utuh.

3

https://www.theguardian.com/world/2015/feb/26 isis-fighters-destroy-ancient-artefacts-mosulmuseum-iraq diakses pada 10 Maret 2017 pada pukul 22.04.
Berkenaan dengan salah kaprah akan pemahaman tersebut, Heath dan Potter menjelaskan bahwa:

Gerakan budaya-tanding sejak awal dirundung oleh kegamangan kronis. Ide bahwa semua politik dipijakkan pada budaya, dan budaya semua ketimpangan sosial disebabkan oleh keajekan yang represif, menyiratkan bahwa tindakan apapun yang melanggar norma-norma sosial konvensional berarti radikal secara politik (2004:76).

Bertolak dari telaah di atas, Heath dan Potter telah menjelaskan bahwa budayatanding (dapat dibaca sebagai perlawanan) tetap pada posisi yang paradoks. Selanjutnya mereka menyebutkan bahwa kegamanan tersebut secara praktis terasa pada segala sesuatu yang melanggar norma sosial yang konvensional berarti radikal. Pun dapat ditambahkan dari telaah Heath dan Potter, bahwa kegamangan ini turut memposisikan gerakan radikal selalu tertaut dengan progresifitas (rival dari konvensional), padahal realitas berkehendak lain. Di mana banyak gerakan radikal justru kembali pada tahap konvensional dengan perubahan yang mengakar. Dalam ihwal ini, kita dapat memahami bahwa radikalisme tidak selalu ditandai dengan konsepsi konvensional ataupun progresif, melainkan adanya sebuah proses yang dilakukan secara mengakar.

Untuk memahami pernyataan di atas, bidang seni rupa Indoenesia rasanya dapat

4

http://edition.cnn.com/2017/01/20/middleeast/palm yra-isis-theater/ diakses pada 8 Maret 2017 pada pukul 10.35 . 
memberikan gambaran singkat. Praktik seni rupa Indonesia, khususnya pada kolonialisme hingga beberapa rezim sebelum orde baru, dapat dikatakan dekat dengan gerakan yang mengakar, semisal pada kecenderungan mooi indie yang menjadi realisme yang kerap dikenal "Jiwa Ketok"- terma dari S. Sudjojono. Merujuk pada penelitian Syamsul Barry (2003), tahapan seni dan radikalisme memang tidak wantah terlihat, namun lazimnya tertaut dengan perubahan. Secara lebih lanjut, Barry menjelaskan bahwa seni dan alat perubahan sudah dilaksanakan sedari dulu, semisal:

Penyebaran Islam di tanah jawa yang menggunakan wayang kulit untuk menceritakan ajaran islam; masa Penjajahan kolonial Belanda yang memfungsikan seni sebagai hadiah pada raja untuk melobi perdagangan; masa revolusi kemerdekaan, karya seni digunakan sebagai media propaganda; pada tahun 1945 di Lawang Jawa Timur, rakyat membuat gambar mural di dinding kota, yang menyarakan bahaya fasisme, imperealisme, dan perlawanan hidup atau mati terhadap tentara Belanda; Seniman LEKRA ketika pemerintahan Bung Karno yang menggunakan karya seni untuk memperjuangkan rakyat dengan mengangkat tema-tema kehidupan rakyat kecil (buruh dan tani) (2003:310).

Ihwal ini bagi Barry didasarkan pada kesadaran atas perubahan yang memunculkan kreativitas baru dalam menciptakan karya seni yang mempunyai nilai-nilai sesuai dengan apa yang terjadi pada konteks persoalan keadaan sosial yang ada di sekitar.

Jika merujuk sejarah, pada masa penjajahan Jepang salah satu ciri pentingnya adalah menyatunya seniman
Indonesia dari berbagai bidang laiknya sebuah paguyuban, yang hubungan erat seniman dengan karya mereka terfokus pada nasib dan perjuangan rakyat. Soedjojono, Hendra Gunawan, Agoes Djaja, Otto Djaja, Harijadi S, Soeromo, Henk Ngantung dan masih banyak lagi pelukis seangkatan mereka yang tampil dengan jati diri dan gaya pengucapan masing-masing. Seni lukis yang dominan pada waktu itu bergaya realisme kerakyatan (2003:322). Dalam ihwal ini, patut disadari bahwa para seniman turut serta dalam melakukan sebuah perubahan, tidak dengan politik praktis, melainkan dengan karya seni lukis gaya realisme. Karya seni yang mereka pilih sebagai medium pun turut didasarkan pada kecenderungan zaman, tentu akan berbeda dengan kini, di mana meme lebih digandrungi sebagai alat melakukan perubahan dengan cara satir ataupun eksplisit.

Dari contoh di atas, satu ihwal yang perlu ditelusuri lebih lanjut adalah terkait perubahan yang dilakukan seniman, di mana para seniman tidak terlacak secara individual, melainkan mereka bergerak secara berkelompok. Pilihan berkelompok ini pun turut terlacak oleh Barry, ia menjelaskan bahwa sanggar-sanggar turut merebak sebagai wadah kegiatan kreatif dan komunikatif para seniman terhadap rakyat, sangar tersebut antara lain: Pelukis rakyat, Seniman Indonesia Muda, Pelukis Indonesia, Sanggar Bambu, Sanggar Bumi Taring, dan lain-lain (2003:32). Ihwal ini menandakan bahwa mereka melakukan sebuah perkumpulan yang bergerak tidak dengan semangat praktis, melainkan ideologis.

Bertolak dari realitas yang terjadi, Barry menyimpulkan bahwa "seni tidak dapat dipisahkan dari politik. Semua saling 
berkait." Senada dengan pernyataan Augusto Boal, yakni seni terbagi dua bagian, seni minor dan seni mayor. Di mana seni minor turut membentuk seni mayor (1979:10). Secara sederhana, Boal menautkan bahwa membentuk seni yang mayor turut didasarkan pada rajutan seni minor dan pelbagai ihwal lain yang berkaitan. Kembali pada kait-mengait antar unsur dalam membentuk seni, seni yang digunakan dalam radikalisme lazimnya bersifat perubahan, dan didukung oleh kelompok sekeliling.

Selanjutnya, seni dan medium perubahan turut tertaut dengan kecenderungan agitasi dan propaganda. Semisal pembakaran patung Soeharto yang dilakukan pada tanggal 11 Maret 1998, di mana para pekerja seni berusaha memanfaatkan semaksimal mungkin media atau alat-alat propaganda di tingkatan strategi untuk memajukan kesadaran sekaligus memberikan arah (2003:339). Secara sederhana, fungsi dari seni yang menyimpan asa agitasi dan propadanga [ketika itu] adalah medium untuk mengenali dan melawan secara lebih jelas dan tersurat. Dengan agitasi dan propaganda, maka pihak yang dilawan terlihat dengan lebih eksplisit, sehingga memahami dan melawan dapat lebih terarah.

Tidak hanya itu, kesimpulan Barry di dalam artikelnya terkait ihwal radikalisme pun cukup menarik. Barry menyatakan: "Karya-karya seni, yang tetap mampu kreatif dan inovatif dalam membayangkan perubahan yang progresif dan revolusioner, yang juga lebih tajam menyambung lidah dan suara rakyat, dan yang selalu segar, personal, dan partikular (2003:360)." Dari pernyataan Barry secara khusus kita ditautkan pada karya seni yang kreatif yang menyambung lidah rakyat dapat menjadi sumber perubahan zaman. Dari sini lah dapat dirunut mengapa seni dapat menjadi gelombang radikalisme. Sebuah gerakan perlawanan yang didasarkan pada seni sebagai agen perubahan yang terlihat lebih sederhana-terlebih dengan karya-, namun terkadang mempunyai implikasi yang lebih dalam. Dengan logika inilah, pernyataan Barry dapat terejawantahkan, di mana ketika karya seni dipentaskan dalam suatu panggung - seperti aksi turun jalan 1998 - maka, yang terjadi adalah: bukan radikalisme yang menyumbang seni, tetapi sebaliknya (2003:360).

\section{Menyingkap Sistem Radikalisme pada Jazz, Hippies, Punk hingga Indie}

Jika menelaah relasi jagad seni dan radikalisme, maka setiap bidang seni mempunyai relasi dan historisnya masingmasing. Telah dibahas di sub-bab sebelumnya di mana relasi seni rupa dan radikalisme memang telah terkait sejak lama. Selain seni rupa, bidang lain yang telah menjadi agen perubahan ketika rezim kolonial, orde lama, dan orde baru adalah teater. Sedangkan cabang seni lainnya, seperti musik dan tari tidak terlalu kuat dalam asa perubahan dan perlawanan ketika era kolonial. Pasalnya tari dan musik-dalam kasus penciptaan-kerap digunakan sebagai medium pemerintah dalam melakukan misi kebudayaan atau jamuan tamu kehormatan lainnya. Alhasil musik dan tari memang menjadi medium seni yang tidak mempunyai posisi tawar dalam perubahan - khususnya pada masa 
kolonial dan orde lama ${ }^{5}$. Berbeda dengan tari, musik di orde lama mempunyai asa perubahan dan melawan. Namun tidak serta-merta ia berubah dengan sekejap, pasalnya musik juga sangat diatur oleh pemerintah.

Seperti ihwalnya kejadian Soekarno yang berpidato di tahun 1959 dengan pesan untuk menghindari imperealisme kebudayaan (Raditya, 2013:50). Pidato tersebut membuahkan pemberhentian pengaruh Barat dan beberapa kebudayaan lain dalam bentuk kebudayaan secara sepihak ketika itu ${ }^{6}$. Alhasil fesyen, tari, makanan, hingga musik dilarang beredar. Berkenaan dengan ihwal tersebut, kendati para distributor dan konsumen akan budaya Barat tetap melakukan praktik jual beli tetapi secara ilegal, namun langkah pembelian tersebut tidak dapat dianggap sebagai upaya radikal. Terlebih cara ilegal tersebut tetap dilakukan secara sembunyisembunyi dan tidak dilakukan secara massal. Kekuatan musik sebagai medium perlawanan barulah cukup terasa dengan aksi lembaga kebudayaan rakyat (LEKRA) ketika di tahun 1965. Mereka menggunakan lagu Genjer-genjer, lagu masyarakat Banyuwangi. Lagu tersebut menjadi lagu yang cukup penting bagi rekan-rekan LEKRA dan PKI ketika itu.

Padahal lagu Genjer-genjer yang diciptakan oleh Muhammad Arief, seorang seniman Banyuwangi menyaratkan kondisi penguasaan Jepang di tahun 1942, dan mengubah lagu tersebut dari lagu dolanan setempat (2014:116). Dengan nada yang dipinjam dari lagu dolanan "Tong Alak Gentak". Selanjutnya Arief mengubah lirik

\footnotetext{
5 http://jurnalruang.com/read/1504175670-maafdilarang-menari-di-sini\# diakses pada tanggal 1 September 2017 pukul 23.59
}

lagu dengan ajukan protes terhadap kependudukan Jepang (2014:117). Barulah pada tahun 1962, Njoto seniman LEKRA terpikat dengan lagu tersebut ketika singgah di Banyuwangi ketika dalam perjalanan ke Bali. Tak lama kemudian, lagu sederhana ini mencapai popularitas yang mencengangkan, dengan sering diputarnya di RRI dan ditayangkan oleh TVRI. Lagu tersebut selanjutnya dipopulerkan oleh Lilis Suryani dan Bing Slamet di tahun 1965 (2004:119).

Dari contoh lagu Genjer-genjer, proses penciptaannya telah dilakukan sejak kependudukan Jepang oleh Muhammad Arief. Lagu tersebut pun dibuat untuk menggambarkan keadaan Indonesia khususnya Banyuwangi pada pemerintahan Jepang. Lagu tersebut memang cukup populer di kalangan masyarakat Banyuwangi, terlebih mengambil pola lagu dolanan yang mereka telah hafal sebelumnya. Namun wacana perlawanan tersebut tidaklah semasif ketika Njoto datang dan tertarik pada lagu tersebut. Dalam ihwal ini kita ditunjukan bahwa populisnya lagu tersebut membutuhkan waktu dan momentum. Dapat dipikirkan apa jadinya jika Njoto tidak singgah di Banyuwangi ketika itu. Ihwal lain yang lebih mendalam adalah, lagu tersebut memang digunakan sebagai medium perlawanan sejak awal, perlawanan pada kekuasaan inilah yang selanjutnya menjadi benang merah bahwa musik berelasi dengan politik.

Namun tidak semua ihwal seni dan radikalisme, atau seni serta perubahan selalu menjadikan seni sebagai partikel

$6 \quad$ baca lebih
http://jurnalruang.com/read/1504165648-ketika-
bung-karno-melarang-dangdut\#
tanggal 1 September 2017 pukul 22.30


semata dalam perubahan. Ada beberapa contoh lain yang sekiranya kuat dan menjadi landasan dalam melakukan perubahan. Salah satu contoh tersebut adalah musik Jazz di awal penciptaannya. Musik Jazz terlahir dari sebuah ketidaksengajaan, di mana bermula sebagai alat komunikasi antar individu ketika itu. Berkenaan dengan ihwal ini, Suka Hardjana mencatat bahwa:

Musik jazz lahir bukan dari golongan masyarakat elite yang kaya, terdidik secara akademis maupun penuh dengan atribut kekuatan dan kekuasaan. Jazz juga tidak lahir dari suatu kelompok masyarakat atau golongan mayoritas yang dominan. Ia lahir dari kelompok minoritas yang terlemah dan terabaikan, para budak dan buruh pekerja perkebunan yang miskin, buta huruf dan sama sekali tidak terdidik, pada saat mereka secara spontan, unik, tetapi sangat ekspresif melantunkan yel kode-kode musik responsis dengan pola-pola ritme Afrika yang sangat dinamis dan berlawanan dengan pola ritme musik Barat yang 'normal', [dan dominan] (2004: 397).

Dari pernyataan Suka di atas, tersemat bahwa musik jazz lahir dari kelompok minoritas, yang lemah dan tidak dianggap. Ihwal yang cukup mengherankan terjadi, di mana para budak Afrika yang tidak mendapatkan pendidikan musik justru dapat membuat pola musikalitas yang berbeda namun membentuk ritme yang dinamis. Kedinamisan dan ketidakpastian musik jazz sebagai nada di awal kemunculannya dianggap sebagai sebuah aktivitas musik yang radikal, melawan tatanan, dan membentuk tatanan baru.
Secara lebih mendalam kedinamisan tersebut membuat perlawanan musikal yang secara lebih lanjut menjadi manifestasi dalam perlawanan budaya, atau budaya tanding. Hardjana turut mengartikulasikan seberapa detil musik jazz dibentuk, yakni: Jazz memberi kebebasan ruang gerak pengucapan diri secara musikal yang lebih leluasa, yang secara umum barangkali sederajad dengan hak individu untuk mengemukakan pendapat secara bebas (Hardjana, 2004:397). Memang yang diungkap Suka Hardjana merujuk pada musikalitas Jazz yang menginsyaratkan pelbagai ihwal, seperti kebebasan, demokrasi, tidak pasti, dinamis, dan sebagainya. Namun secara pembentukannya, musik tersebut terlahir dari nada-nada balasan, layaknya interlocking dalam musik antar satu budak ke budak lain. Ketika menjadi musik pun, Jazz tidak dihadirkan layaknya musik klasik pada resto mewah, melainkan di barbar kecil para budak berkumpul. Dari pembentukan sosial yang kontekstual hingga musikal, dapat dilihat bahwa jazz menawarkan sebuah perubahan yang ideologis. Di mana dilakukan sebagai alat komunikasi antar satu dengan yang lain untuk menyusun serangan atau bahkan untuk menegosiasikan rasa ketika ditindas. Lalu nada-nada tersebut mereka bawa dan olah pada sebuah daya musik yang justru menawarkan ihwal yang berbeda, seperti improvisasi, penggunaan nada yang tidak lumrah dan asing. Ihwal 'nyeleneh' tapi beralasan, dan tidak arbriter. Melawan pada sebuah sistem yang bahkan tertanam pada musikalitas musik ketika itu, terstruktur dan rapih.

Medium perlawanan yang bertolak dari musik menjadikan seni menjadi kerangka penting dalam perubahan. 
Memang tidak dapat dipungkiri ada penindasan kaum rasial tertentu di dalam musik Jazz, namun perlu diingat bahwa melalui musik mereka justru dapat mengekspresikan secara lebih terang hingga posisinya kini menjadi musik yang cukup tinggi dibanding genre-genre lainnya. Selain secara global, jazz juga berkembang di Indonesia. Tercatat bahwa W.R. Supratman pun memulai karirnya sebagai pemusik jazz. Selain itu musisi jazz internasional turut datang ke Indonesia untuk menghibur tentara Belanda yang menjaga koloninya (Barendgert dan Bogaerts, 2016:19-20). Beberapa tahun sebelumnya, jazz di Indonesia telah populer pada tahun 1920, namun persebarannya di kalangan tertentu saja, mulai dari kalangan orang Belanda dan beberapa kalangan Eropa lainnya, serta segelintir kaum intelektual dan menengah ke atas Indonesia (Sakrie, 2015:9).

Adapun contoh lain selain musik jazz, yang dirasa terbentuk secara ideologis, yakni golongan Hippies dan musik punk. Hippies merupakan sub-kultur yang muncul pada tahun 1960an sebagai budaya-tanding dengan gerakan menolak kehidupan mainstream Amerika (Shires, 2006:90). Gerakan ini terorganisir di kampus di Amerika, dan menyebar di negara lain, termasuk Canada dan Britain. ${ }^{7}$ Gerakan ini turut muncul ketika perang Saigon di Vietnam berlangsung ${ }^{8}$. Dalam ihwal ini, Hippies muncul sebagai aksi perlawanan, budaya tanding dari budaya yang kuat di masyarakat. Jika merujuk pada Heath dan Potter, bentuk Hippies pun turut menarik diperhatikan, yakni:

\footnotetext{
${ }^{7}$ https://www.britannica.com/topic/hippie diakses pada 2 Maret 2017, pukul 21.00
}

Maka hippies generasi pertama, pun berbuat sebisanya untuk melanggar tata krama berbusana masyarakat tahun 1950an: yang lelaki memanjangkan rambut juga cambang, tak mau pakai kemeja dan dasi; yang perempuan memakai roki mini, mencopot kutang, dan berhenti berias, dan seterusnya. Namun tak lama kemudian aneka asesoris dan gaya dandanan ini pun mulai bermunculan dalam iklan-iklan dan di manekin jendela-jendela toko. Dengan kata lain, "sistem" sepertinya menanggap hippies lebih sebagai peluang pemasaran ketimbang ancaman terhadap kemapanan. (2004:420). Dari pernyataan di atas, kendati mereka menyebutkan tindak lanjut dari hippies adalah proses komodifikasi, namun poin utama yang ingin dikemukakan adalah bentuk yang eksplisit ditunjukan sebagai pengejewantahan atas budayatanding. Mulai dengan melanggar aturan dan tata krama, hingga gaya hidup mereka. Ihwal ini menjadi menjamur di pelbagai tempat, sebagai sebuah gerakan, dan gaya hidup. Dapat dilihat bahwa pemuda Amerika mempunyai kuasa mengubah yang cukup signifikan. Mereka melawan dengan cara yang tidak terkira, dengan gerakan yang kontra-produktif jika ditautkan pada budaya mainstream. Mereka melakukan pelbagai tindakan yang berbeda dan asing untuk dilakukan. Namun mereka bukan melakukan untuk mencari kesenangan, melainkan protes terhadap kebudayaan mainstream di tempat tertaut.

Tidak jauh berbeda, ihwal ini turut mempengaruhi genre punk yang terlahir di

\footnotetext{
$8 \quad$ http://www.history.com/topics/vietnamwar/vietnam-war-protests diakses pada 4 Maret 2017, pukul 10.10
} 
Inggris pada tahun $1976^{9}$. Genre tersebut cukup berkembang sebagai wacana perlawanan dan budaya tanding ketika itu. Di mana mereka berasal dari kelas pekerja, bergaya lusuh, 'kotor' dalam pengenaan pakaian dan penggunaan bahasa, tetapi di saat yang sama mereka menjadi medium ejekan dari ironi kelas pekerja. Ihwal ini turut diartikulasikan oleh Dick Hebdige (1979:26) yang menyatakan:

Punk reproduced the entire sartorial history of post-war working-class youth cultures in 'cut up' form, combining elements which had originally belonged to completely different epochs. There was a chaos of quiffs and leather jackets, brothel creepers and winkle pickers, plimsolls and paka macs, moddy crops and skinhead strides, drainpipes and vivid socks, bum freezers and bovver boots - all kept 'in place' and 'out of time' by the spectacular adhesives: the safety pins and plastic clothes pegs, the bondage straps and bits of string which attracted so much horrified and fascinated attention. Punk is therefore a singularly appropriate point of departure for a study of this kind because punk style contained distorted reflections of all the major post-war subcultures.

Merujuk pada pernyataan Hebdige, bahwa punk mereproduksi keseluruhan sejarah sartorial budaya pemuda kelas pekerja pasca perang dengan semangat yang berangkat dari titik tolak refleksi atas subkultur pasca perang dunia. Pun genre tersebut tertaut pada keterasingan, sentimen

\footnotetext{
9 http://subcultureslist.com/punks/ diakses pada tanggal 10 Maret 2016 , pukul 14.30
}

kelompok, anarki, dan pelbagai ihwal melawan lainnya. Langkah ini mereka lakukan untuk menunjukan bahwa masyarakat berbasis konsumen yang bergerak keluar dari kemakmuran ekonomi, sosial, dan politik praktis. ${ }^{10}$

Merujuk pada keberadaannya kini, genre ini telah menyebar ke seluruh dunia. Masih terkait dengan pola perlawanan hippies, sebenarnya punk memiliki ihwal yang serupa, namun yang membedakan adalah sistem yang mereka bangun. Terkait ihwal ini, Heath dan Potter menyatakan bahwa:

Sebagian besar etos punk dipijakkan pada penolakan atas apa yang dijunjung oleh kaum hippies. Kalau mereka mendengarkan Lovin' Spoonfil, kami anak punk mendengarkan Grievous Bodily Harm. Kalau mereka Rolling Stones, kami Violent Femmes, Circle Jerks, dan Dead on Arrival. Kalau mereka berambut gondrong, kami jabrik Mohawk. Kalau mereka pakai sandal, kami pakai bot tentara. Kalau mereka ikut-ikut satyagraha, kami aksi langsung. Punk adalah "bukan-hippies" (2004:17).

Dari penjelasan di atas, tegas rasanya pola yang dilakukan antara hippies dan punk memang pada pijakan yang sama, yakni melawan sistem. Namun secara lebih lanjut, mereka membedakan secara praktis, mulai dari lagu yang didengarkan, hingga potongan rambut, dan sepatu yang digunakan.

10 ibid. 
Michael HB Raditya, Mengartikulasikan Musik dengan Radikalisme

\begin{tabular}{|c|c|}
\hline Lirik yang mempengaruhi kaum hippies & Lirik yang mempengaruhi anak Punk \\
\hline Lovin' Spoonfil - Summer in the City & Grievous Bodily Harm - Sick Boy \\
\hline Hot town, summer in the city & $\begin{array}{l}\text { I'm strapped into my bed, I've got electrodes in } \\
\text { my head. }\end{array}$ \\
\hline Been down, isn't it a pity & $\begin{array}{l}\text { My nerves are really bad, it's the best time I've } \\
\text { ever had. }\end{array}$ \\
\hline Doesn't seem to be a shadow in the city & I'm a sick boy and there's no cure. \\
\hline All around, people looking half dead & I'm a sick boy there should be more. \\
\hline $\begin{array}{l}\text { Walking on the sidewalk, hotter than a match head } \\
\text { But at night it's a different world }\end{array}$ & But I'm happy the way I am, like a sardine in can. \\
\hline Go out and find a girl & People taking notes, people in white coats. \\
\hline Come-on come-on and dance all night & $\begin{array}{l}\text { I see school girls everywhere, short skirts and } \\
\text { pig-tailed hair. }\end{array}$ \\
\hline $\begin{array}{l}\text { Despite the heat it'll be alright } \\
\text { And babe, don't you know it's a pity }\end{array}$ & $\begin{array}{l}\text { But why must I suffer, for being a gym slip } \\
\text { lover? }\end{array}$ \\
\hline That the days can't be like the nights & \\
\hline In the summer, in the city & \\
\hline In the summer, in the city & \\
\hline Cool town, evening in the city & \\
\hline Dressing so fine and looking so pretty & \\
\hline Cool cat, looking for a kitty & \\
\hline Gonna look in every corner of the city & \\
\hline Till I'm wheezing like a bus stop & \\
\hline Running up the stairs, gonna meet you on the rooftop & \\
\hline But at night it's a different world & \\
\hline Go out and find a girl & \\
\hline Come-on come-on and dance all night & \\
\hline Despite the heat it'll be alright & \\
\hline And babe, don't you know it's a pity & \\
\hline That the days can't be like the nights & \\
\hline In the summer, in the city & \\
\hline
\end{tabular}


Di atas adalah teks dari masing-masing band yang menjadi acuan Hippies (kiri) dan Punk (kanan). Dalam musik jelas berbeda, di mana G.B.H. bertempo cepat dengan lirik yang sedikit namun kerap dilakukan repetisi, teksnya pun menjelaskan kekacauan diri yang ada. Sedangkan Lovin' Spoonful bertempo mengayun dengan lirik yang artikulatif dan menstimulasi imaji atau keinginan tertentu. Kedua jenis band sangat berbeda musikalitas dan teks. Namun kedua band ini yang setidaknya mereka acu masing-masing dalam melawan.

Selain musik dan gaya hidup yang jelas berbeda, jangan sekali-sekali menyamakan mereka karena alasan pola melawan yang serupa, pasalnya: Kebencian [punk] terhadap hippies bukan karena mereka terlampau radikal, melainkan mereka kurang radikal. Mereka telah 'menjual' diri. Mereka itu, sebagaimana Cobain menyebutnya adalah kaum "hippierkrit" (Heath dan Potter, 2004:17). Maka dari sinilah tampak jelas mengapa punk tidak menyenangi hippies, karena persoalan komodifikasi pada hippies itu sendiri. Secara lebih gamblang, Heath dan Potter mengungkap bahwa:

Di sini orang bisa melihat dengan cukup jelas bahwa kendati Cobain dan kaum punk selebihnya boleh jadi menampik sebagian besar ide yang berasal dari budaya-tanding kaum hippies, ada satu unsur gerakan itu yang kami telan bulat-bulat dan mentah-mentah, adalah bahwa kami tidak seperti mereka, kami takkan pernah menjual diri. Kami akan melakukannya dengan benar (2004:180).
Layaknya dendam kesumat atas Punk terhadap Hippies yang termodifikasi, maka punk berikrar tidak akan 'menjual diri' atau memodifikasi, bahkan termodifikasi.

Namun malang tidak dapat ditolak, apa kabar dengan punk kini? Apakah genre tersebut tidak termodifikasi? Tidak ikut arus musik dunia, atau Indonesia? Bertolak dari ihwal ini Heath and Potter menjelaskan bahwa:

Kurt Cobain, kendati ia menganggap dirinya pemusik punk, seseorang yang kerjanya membuat musik "alternatif", rekamannya toh terjual jutaan keping. Berkat Cobain, musik yang dulunya disebut "hardcore" kini punya label lain dan dijual kepada umum sebagai "grunge". Namun, alih-alih menjadi sumber kebanggan, popularitas inimalah memuatnya [Cobain] malu terus menerus. Keraguan merongrong [di] belakang kepalanya, membisikan bahwa ia telah "menjual diri" dan "ikut arus" (2004:16).

Dalam ihwal ini, Cobain yang hidup dengan gaya punk dengan koridor alternatif justru menjadi musik yang dominan. Ia telah menjual genre perlawanan tersebut untuk ikut pada arus dominan. Sebenarnya, beberapa upaya dari Nirvana dalam melakukan upaya kontra-produktif, agar para penggemar meninggalkannya telah dilakukan, sepert "album Nirvana, In Utero, jelas-jelas dimaksudkan sebagai musik sulit yang tak bisa didengar orang. Namun upaya tersebut gagal. Album ini melesat ke nomor satu di tangga Billboard (Heath dan Potter, 2004:16)." Alhasil ihwal inilah yang menjadi salah satu pemicu atas alasan bunuh diri Kurt Cobain, yakni 
ideologi yang termodifikasi. Namun di luar itu semua, kita telah melihat bahwa punk atau hippies muncul bukan karena keinginan praktis, melainkan ideologis, perubahan dan perlawanan.

Selain dari tiga contoh kasus di atas, salah satu ihwal yang cukup dekat dengan pola 'radikalisme' pada era kekinian adalah musik Indie. Musik indie yang tengah mendapatkan eksistensinya kini memang tidak dapat diindahkan. Posisi musik indie cukup menggoda bagi pasar, alhasil dapat kita lihat kecenderungan komodifikasi musik indie. Namun beralih jauh dari ihwal tersebut, pola terciptanya musik Indie cukup radic. Mereka jelas melakukan budaya-tanding, mereka turut melawan industri musik global dan mainsteam. Bertolak dari ihwal tersebut, Luvaas menyatakan bahwa:

Being independent of the majors, thus, was as much existential as a practical claim. I was never really abot the music industry. It was about seizing control over creative expression, and by extension, forging one's own, autonomous way of being and living in the world (2012:127)

\section{Melawan dan Membentuk Konstelasi}

Pada awalnya, tidak dapat ditampik bahwa menautkan radikalisme dengan musik di Indonesia terbilang sulit. Pasalnya, baik musik program juga musik absolut, ataupun musik genre yang dianggap Theodor Adorno terstandarisasi (dalam hal ini musik pop) ${ }^{11}$, kerap ditautkan pada ranah psikologi atau neuroscience. Perspektif psikologi menautkan dampak musik bagi

11

http://www.icce.rug.nl/ soundscapes/DATABASE seorang individu, yang secara sederhana dapat dikorelasikan dengan terapi musik, baik yang sifatnya penyembuhan, ritual, atau hukuman (Djohan, 2006: 55, 57, 106). Atau implikasi musik di dalam otak yang tergambarkan fluktuatif karena daya rangsang musik pada neuroscience. Pada kerangka tersebut, musik mempunyai peran internal di dalam tubuh manusia, dan musik memang menjadi medium dalam mencapai sebuah ihwal.

Namun ihwal yang tidak kalah menarik justru terjadi pada pola yang terjalin bersamaan dengan aktivitas manusia. Berkenaan dengan ihwal tersebut, beberapa cabang ilmu turut mengakomodasi, semisal: studi sejarah, antropologi, sosiologi, hingga cultural studies. Cabang ilmu tersebut turut serta mengartikulasikan musik dan relasinya dengan manusia. Namun dari ihwal ini, cabang ilmu tersebut menautkan musik dan pelbagai aktivitas eksternal manusia. Sederhananya adalah aktivitas praktis manusia dengan musik. Aktivitas praktis tersebut beririsan dengan pelbagai tingkah laku manusia dengan musik tanpa terkecuali, maka dari bingkai tersebutlah justru perkara jazz, hippies, punk, dan indie di atas dapat terbahasakan dengan baik. Di mana akhirnya kita mengetahui bahwa musik dapat menjadi budaya-tanding dari budaya mainstream tertentu.

Bertolak dari ihwal musik seperti Jazz, hippies, punk, dan indie pun terlihat sangat signifikan, sebut saja musik klasik, gereja, dan musik jazz di Amerika; musik pop dan musik hippies; musik hippies, pop, folk, dan musik punk; serta musik mayor label dan musik indie label. Dari pembanding

S/SWA/On_popular_music 1.shtml diakses pada 14 Maret 2017, pukul 15.58. 
tersebut, dapati dilihat bahwa setiap perubahan didasarkan pada dua elemen yang kuat, elemen sebelum dilakukan perubahan dan elemen setelah perubahan berlangsung, semacam oposisi biner. Mempunyai dua ihwal yang bertentangan sebagai medium perubahan. Senada dengan ihwal tersebut, Heath dan Potter (2004:160) turut mengamini dengan menyatakan:

Maka pemberontakan budayamenolak norma-norma masyarakat "umum"—jadi berfungsi sebagai sumber pembeda yang layak diperhitungkan. Dalam masyarakat yang menjunjung individualisme dan membenci kerseragaman, "jadi pemberontak" kini dianggap sebagai kategori aspirasi baru. Pada tahun '60-an, menjadi seorang beat atau hippies adalah cara untuk menunjukan bahwa anda bukanlah salah satu orang kolot atau konservatif itu. Pada tahun '80-an, berdandan punk atau gothik menjadi cara untuk menunjukan bahwa anda bukan seorang culun atau eksmud. inilah cara mengirimkan pesan bahwa "Aku, tidak seperti kalian, tidaklah diperdaya oleh sistem ini”.

Maka menolak dan membuat pembeda yang jelas dari sebelumnya menjadi langkah utama. Hal ini pun turut diungkap oleh Sheila Whiteley (1992:2) yang menyatakan bahwa:

What is especially interesting is that contemporary analysts should draw attention both to the divisions within the movement and to the broad consistency in their antagonistic position towards the dominant culture. As Roszak points out, 'What makes the youthful disaffiliation of our time a cultural phenomenon rather than a political movement, is that it strikes beyond ideology to the level of consciousness, seeking to transform our deepest sense of the self, the environment.

Bahkan terma pemberontak dan antagonis turut digunakan sebagai penggambaran dari perubahan yang signifikan, dengan contoh punk dan hippies. Di luar itu semua, perlawanan mempunyai pesan yang tidak kalah penting adalah menghindari keterperdayaan oleh sistem. Dalam ihwal ini dominasi dan alienasi menjadi tujuan perlawanan tersebut.

Alhasil sebuah gerakan radikal yang tersemat budaya-tanding tahu benar apa yang dilawan oleh mereka, dan seberapa dalam ihwal tersebut berpengaruh kepada masyarakat. Secara lebih gamblang, gerakan mereka membuat sebuah kekacauan dari sistem yang telah tersusun. Ihwal ini menandakan bahwa budaya tanding tertentu melakukan upaya perubahan yang mendalam, namun mereka yang didasarkan pada seni [dalam ihwal ini musik], mempunyai sebuah tawaran alternatif yang tegas dan mendalam. Perubahan tersebut tidak dilandaskan pada tingkah yang sekali jalan, melainkan sebuah kesadaran yang menyeluruh. Terlebih karena yang dilawan dari budayatanding adalah sistem yang kokoh, maka tawaran baru memerlukan sebuah sistem baru, yang berbeda dengan sistem sebelumnya. Ihwal itulah yang menyimpan semangat radikal, di mana pergantian budaya dari yang mainstream menjadi alternatif dapat diterapkan dengan persiapan sistem yang matang. Alhasil perubahan dapat meliputi segala konstelasi 
budaya yang baru, kebudayaan yang ingin dicapai. Namun ada satu catatan yang perlu dipegang-teguh, di mana Bila semua orang ikut budaya-tanding, maka budaya-tanding itu jelas berubah jadi budaya mainstream. Maka sang pemberontak harus mencitakan budaya-tanding baru, untuk menarik kembali garis beda itu. Gaya budayatanding, berawal sebagai sesuatu yang sangat ekslusif (Heath dan Potter, 2004:161). Pernyataan tersebut mengajak kita semua untuk terus mengkritisi kebudayaan yang ada, terlebih ketika budaya alternatif menjadi mainstream. Jika ihwal tersebut terjadi maka diperlukan sebuah perubahan baru. Maka begitulah posisi kebudayaan, di mana inovasi atau sebuah perubahan diperlukan, dengan mengkontestasikannya dengan budaya lama, dan radikalisme terkadang menjadi jalan ideal dalam pencapaian yang diinginkan oleh masing-masing kelompok, golongan, atau bangsa.

\section{PENUTUP}

Radikalisme muncul dan berkembang tidak sembarang, gerakan tersebut muncul didasarkan pada sebuah alasan yang mengakar. Tidak peduli benar atau salah, namun radikalisme melakukan sebuah perubahan yang signifikan. Dalam ihwal lain seperti agama dan politik, radikalisme berkerja dengan cepat. Namun pada ihwal seni, radikalisme perlu ditelaah ulang. Terlebih radikalisme di dalam seni tidak dapat disama-ratakan dengan radikalisme pada politik dan agama. Jika bertolak dari contoh kasus yang ditautkan, penggunaan lagu genjer-genjer dalam konstelasi politik PKI ketika itu; kemunculan genre Jazz yang menawarkan sebuah rasa musikal yang berbeda; hippies dengan gerakan melawan kebudayaan mainstream Amerika; punk yang muncul karena kelas pekerja yang signifikan, sehingga sebuah perubahan yang mengakar perlu dilakukan; ataupun musik indie yang menyusun sistem baru dalam mengganti sistem lama.

Dari pelbagai contoh tersebut kita disadarkan bahwa yang telah mereka lakukan adalah menimbulkan budaya tanding atas budaya yang lama, namun yang mereka lakukan tidak tanggungtanggung, dengan beragam negosiasi yang dilakukan. Justru budaya tanding perlu disegerakan, maka paham radikal yang mengakar menjadi sebuah formula paling tegas. Ihwal ini pun dapat dilihat secara gamblang, di mana individu atau kolektif yang tergabung, entah hippies, punk, jazz, atau indie sekalipun, tidak bernegosiasi dengan budaya mainstream. Jika hippies dan punk hingga mempunyai alunan musik dan gaya berbusana tertentu, indie turut mempunyai pola produksi, distribusi, dan konsumsinya sendiri. Lantas gerakan radikal apa lagi yang dapat diingkari? Walaupun tidak dapat disangkal bahwa individu atau kolektif yang tergabung tidak membabi-buta dalam menuntut orang lain ikut serta. Namun ada satu ihwal yang ditawarkan untuk mereka yang berada pada budaya mainstream, yakni seni atau musik itu sendiri-entah alunan ritmis, hingga teks-yang menjadi medium dalam menstimulasi orang lain menyadari akan perlunya perubahan yang signifikan dan mengakar. Alhasil musik tidak hanya menjadi partikel dalam konstelasi, tetapi ia dapat menjadi penentu utama dalam pembentukan konstelasi kebudayaan bermasyarakat. $* * * *$ 


\section{DAFTAR PUSTAKA}

Abbas, Tahir. 2007. Islamic Political Radicalism: A European Perspective. Edinburgh: Edinburgh University Press.

Asy'ari, Deni. 2009. "Radikalisasi Gerakan Keagamaan Mahasiswa Non Studi Keagamaan dalam Gerakan Islam Radikal", sebagai Tesis Program Studi Sosiologi, Pascasarjana Fakultas Ilmu Sosial dan Politik, UGM.

Barry, Syamsul. 2003. "Radikalisme dalam Seni: Seni pada Aksi Unjuk Rasa Turun Jalan", dalam Politik dan Postkolonialitas di Indonesia, Budi Susanto (ed.). Yogyakarta: Penerbit Kanisius dan Lembaga Studi Realino, halaman 309-360.

Bart Barendgert dan Els Bogaerts. 2016. Merenungkan Gema: Perjumpaan Musikal Indonesia - Belanda. Jakarta: Buku Obor.

Boal, Augusto. 1979. Theatre of the Oppressed. London: Pluto Press.

Djohan. 2006. Terapi Musik: Teori dan Aplikasi. Yogyakarta: Galangpress.

Hadrjana, Suka. 2004. Antara Kritik dan Apresiasi. Jakarta: Penerbit Buku Kompas.

Heath, Joseph dan Andrew Potter. 2004. Radikal itu Menjual: Budaya perlawanan atau Budaya Pemasaran? Jakarta: Antipasti.

Hebidge, Dick. 1979. Subculture: The Meaning of Style. London: Routledge.

Jauhari, Kalam. 2016. "Radikalisasi Buruh Kereta Api di Perkotaan Jawa 19141926", sebagai Tesis Program Studi Sejarah, Pascasarjana Fakultas Ilmug budaya, UGM.
Kartodirjo, Sartono. 1987. Pengantar Sejarah Indonesia Baru, 1500-1900: Dari Kolonialisasi sampai Nasionalisme. Jakarta: PT. Gramedia Pustaka Utama. 1992. Ratu Adil. Jakarta: Sinar Harapan. Laclau, Ernesto dan C. Mouffe. 1986. Hegemony and Socialist Strategy. London: Verso.

Luvaas, Brent. 2012. DIY Style: Fashion, Music and Global Digital Cultures. London: Berg Publishers.

Olcott, M.B. 2007. Roots of Radical Islam in Central Asia. New York: Carnegie Endownment for International Peace. Raditya, Michael H.B. 2013. "Esensi Senggakan pada Dangdut Koplo sebagai Identitas Musikal”, sebagai tesis pada program Pengkajian Seni Pertunjukan dan Seni Rupa, Sekolah Pascasarjana, Universitas Gadjah Mada.

Rez, Idhar. 2008. Music Records Indie Label. Bandung: Mizan.

Rosadi, Andri. 2006. "Gerakan Radikal Keagamaan (Studi Antropologi atas Gerakan Front Pembela Islam di Jakarta", sebagai Tesis Program Studi Antropologi, Pascasarjana UGM.

Sakrie, Denny. 2015. 100 Tahun Musik Indonesia. Jakarta: Gagas Media.

Salam, Abdul. 2004. "Radikalisme Islam: Studi Tentang Gerakan

Majelis Mujahidin Indonesia”, sebagai Tesis Program Studi Sosiologi, Pascasarjana Fakultas Ilmu Sosial dan Politik, UGM.

Seligman, Erwin R.A., 1972. Encyclopedia of Social Science vol XIII-XIV. New York: The Macmillan Company. 
Shires, Preston. 2006. Hippies of The Religious Right. Texas: Baylor University Press.

Tim Narasi. 2009. 100 Tokoh yang Mengubah Indonesia. Yogyakarta: Penerbit Narasi. Whiteley, Sheila. 1992. The Space Between The Notes: Rock and the Counter Culture. London: Routledge.

Zulkifli, Arif, Purwanto Setiadi, dkk. 2014. "Mati Sunyi Pencipta Genjer-genjer" dalam Seri Buku Tempo Lekra dan Geger 1965. Jakarta: Kepustakaan Populer Gramedia, halaman: 114-122.

\section{Wesbite}

https://www.theguardian.com/world/ 2015/feb/26/isis-fighters-destroyancient-artefacts-mosul-museumiraq http://edition.cnn.com/2017/01/20/m iddleeast/palmyra-isis-theater/ https://www.britannica.com/topic/hi ppie http://www.history.com/topics/vietn am-war/vietnam-war-protests http://subcultureslist.com/punks/ http://www.icce.rug.nl/ soundscapes /DATABASES/SWA/On_popular music_1.shtml http://jurnalruang.com/read/1504165 648-ketika-bung-karno-melarangdangdut\# http://jurnalruang.com/read/1504175 670-maaf-dilarang-menari-di-sini\# (diakses tanggal 4 Maret 2015 pukul 18.20 WIB) 